\title{
PUMA Kills Stem Cells to Stall Cancer?
}

\author{
Jian Yu \\ University of Pittsburgh Cancer Institute and Department of Pathology, University of Pittsburgh \\ School of Medicine, Pittsburgh, Pennsylvania
}

PharmSight on Qiu W, et al. PUMA suppresses intestinal tumorigenesis in mice. Cancer Res 2009;69:49995006.

\begin{abstract}
Apoptosis evasion is a hallmark of human cancer. PUMA is a BH3-only $\mathrm{Bcl}-2$ family protein that mediates both p53-dependent and independent apoptosis. However, its role in tumor suppression had not been well established. Our recent work provides direct evidence that PUMA plays an important role in suppressing intestinal tumorigenesis in two mouse models including (i) the azoxymethane (AOM)/dextran sulfate sodium salt (DSS)-treated mice and (ii) $A P C^{\mathrm{Min} /+}$ mice. The activities of PUMA appeared to be in the intestinal stem cells, and involve both p53-dependent response to DNA damage, and p53-independent mechanisms triggered by inflammation. Our data suggest that the interplay between different apoptotic pathways in intestinal stem cells underlie the initiation of intestinal carcinogenesis, and should be considered in the context of cancer prevention and therapy.
\end{abstract}

Keywords: PUMA; p53; Apoptosis; Colon cancer; Stem cells

\section{Introduction}

The multi-step carcinogenesis process involves the accumulation of a series of genetic and epigenetic alterations $(1,2)$. A number of features distinguish cancer cells from their normal counterparts. Resistance to apoptosis is a hallmark of virtually all types of human cancer, and leads to increased risk of clonal expansion of cells containing neoplastic alterations (3). Colon cancer is perhaps the most well studied model that illustrates this

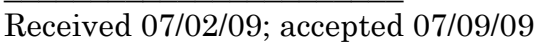

Correspondence: Jian Yu, Ph.D., Hillman Cancer Center Research Pavilion, Suite 2.26h, 5117 Centre Ave, Pittsburgh, PA 15213, USA. Tel. 412-623-7786, Fax. 412623-7778. email: yuj2@upmc.edu multi-step nature (2). Apoptosis, a major mechanism regulating turnover of intestinal epithelial cells, is progressively inhibited in colon carcinogenesis $(4,5)$. This is in part attributed to frequent mutations in tumor suppressors APC (adenomatous polyposis coli) and $p 53$, and in oncogenes $\beta$-catenin, K-ras, BRAF, and $P I 3 K$ (2). In addition, overexpression of antiapoptotic proteins such as Bcl-2, Bcl-xL, and survivin are also common in cancer (6). These alterations can directly or indirectly suppress apoptosis and subsequently drive other tumorigenic events leading to cancer (3). However, direct in vivo evidence supporting the role of apoptosis in tumor suppression, especially in solid organs, is generally scarce. Using mice deficient in the proapoptotic Bcl2 family protein PUMA, we demonstrated that both p53-dependent and independent apoptosis contribute to the suppression of malignancies in the intestinal tract (7).

\section{Material and Methods}

The procedures of animal work and various methods for Western blotting, caspase 3 and BrdU immunohistochemistry have been previously described (7). The HCT 116 and its isogenic p53 knockout ( $553 \mathrm{KO}$ ) cells have been previously described (8).

\section{Results and Discussion}

The role of BH3-only proteins in tumor suppression

The Bcl-2 family proteins are evolutionarily conserved key regulators of apoptosis which include both antiapoptotic and proapoptotic members. PUMA (p53 upregulated modulator of apoptosis) was originally identified as a transcriptional target of p53 and a BH3-only protein that induces rapid and potent apoptosis in various cancer cells (9-12). 
Similar to other BH3-only proteins, PUMA serves as a proximal signaling molecule which transduces death signals via multidomain Bcl-2 family members to induce mitochondrial dysfunction and caspase activation $(13,14)$. PUMA primarily acts to indirectly activate Bax and/or Bak by relieving the inhibition of these proteins by antiapoptotic Bcl-2 family members (15). PUMA-deficient human or mouse cells from various tissue origins including the intestinal tract have profound apoptotic deficiencies in response to a wide variety of stresses, establishing its principle role in promoting apoptosis $(13,16-19)$.

The Bcl-2 family proteins are linked to cancer. Genetic alterations of Bcl-2, the founding member of the family, are responsible for a subset of leukemia. Several prosurvival family members, including Bcl-2, Bcl-xL and Mcl-1, are frequently overexpressed in colon cancer and other human malignancies. In rare cases, the proapoptotic member $B A X$ is mutated in mismatch repair-deficient colon cancer (20). On the other hand, the BH3-only proteins including PUMA are not inactivated by mutations in cancer $(21,22)$. Several lines of evidence however suggest that the function of PUMA is frequently compromised in cancer as a result of p53 dysfunction (23), overexpression of the antiapoptotic Bcl-2 family members (24), reduced expression due to promoter methylation (25), or activated oncogenic kinase pathways including PI3K/AKT (26-28). Our work now provides direct evidence for a role of PUMA in suppressing carcinogenesis in two intestinal tumor models, the AOM/DSS carcinogenic model and the $A P C / \mathrm{min}$ genetic model (7). Our findings are in agreement with previous studies suggesting a tumor suppressor role of PUMA (29, 30) and Bim (31), another BH3-only protein, in lymphomagenesis in mice. Together, these observations establish a critical role for BH3-only proteins in tumor suppression and their deregulation in cancer in the absence of genetic alteration.

\section{Apoptosis induction as a critical tumor suppressor function of $\mathrm{p} 53$}

The p53 tumor suppressor is essential for preventing inappropriate cell proliferation and for maintaining genome integrity following genotoxic stress $(32,33)$. The function of p53 is multifaceted and not restricted in the nucleus, while transcriptional activation by $\mathrm{p} 53$ appears to be essential for its proapoptotic function in vitro and in vivo (34). The great majority of tumor-derived p53 mutants are defective in apoptosis induction and unable to transactivate proapoptotic downstream targets such as PUMA and Noxa (23). Genes encoding proteins involved in virtually every step of apoptosis can be regulated by p53 (23). However, a lingering question is how does p53-depependent apoptosis stop cancer? Loss of p53 in mice results in early onset lymphomas and animal death, which provides little insights on how it acts as a tumor suppressor in solid organs (35). There is little doubt that PUMA accounts for much of the proapoptotic activity of p53 in response to DNA damage in vivo, and the induction of PUMA by DNA damage is strictly p53-dependent (9, 11, 13, 36, 37). Nevertheless, PUMA-deficient mice did not develop spontaneous tumors more readily compared to their WT counterparts under pathogen free conditions (16, 17).

Our recent work indicates that the tumor suppressive activities of PUMA are more pronounced following DNA damage through a p53dependent mechanism in the intestinal tract (7). The induction of PUMA by AOM in colonic epithelial cells in culture was also dependent on p53 (Figure. 1A). This would suggest that p53 guards against DNA damage to suppress oncogenesis through induction of PUMA and apoptosis. Loss of PUMA or p53 significantly blocked AOM-induced apoptosis while only minimally impacting cell proliferation, if at all (7) (Figure. 1B). Our findings are consistent with an earlier finding that an intact p53 pathway suppressed AOM-induced colon carcinogenesis (38). However, another study suggested that p53dependent apoptosis in response to DNA damage is not important for tumor suppression (39). In this study, the authors used a mouse model in which p53 can be switched on or off to show that the p53mediated pathological response to whole-body irradiation is not required for suppression of radiation-induced lymphoma. This conclusion perhaps does not apply to carcinomas. Moreover, Noxa, another BH3-only protein, can sometimes substitute or work together with PUMA to mediate p53-dependent apoptosis following DNA damage (17, 37). It would be of interest to explore whether Noxa is also involved in p53-dependent tumor suppression in similar models.

\section{Does colon cancer arise from mutated colonic stem cells?}

The intestinal epithelium is the fastest renewing tissue in the human body and is regenerated by stem cells located at the bottom of the crypts, which supply all differentiated cell types (40). 


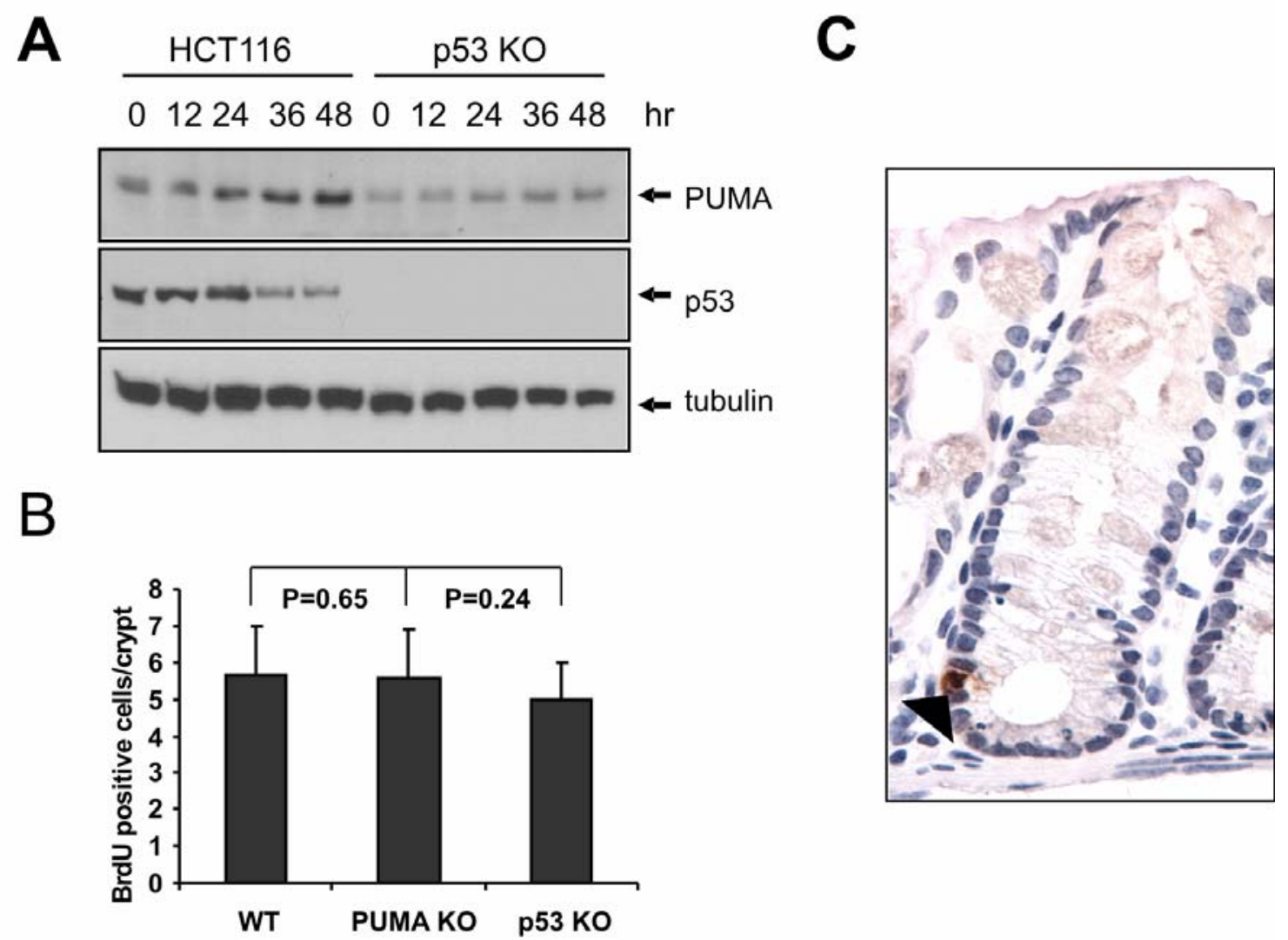

Figure 1. p53-dependent PUMA induction contributes to AOM-induced apoptosis but not proliferation. (A) The parental or p53 KO HCT116 cells were treated with $20 \mathrm{ng} / \mathrm{ml}$ AOM for the indicated time. The levels of PUMA, p53 and tubulin were analyzed by Western blotting. (B) The proliferation of the colonic crypts was determined by BrdU immunohistochemistry (IHC) in WT, PUMA KO and p53 KO mice 72 hr following AOM injection. (C) Active caspase-3 (brown, arrow head) in the colonic crypts $8 \mathrm{hr}$ after AOM injection was detected by IHC.

Differentiated enterocytes are constantly removed by apoptosis after migrating to the top of the villus $(4,41)$. What is the cellular origin of intestinal tumors? Are they derived from stem cells that have endured critical mutations in a certain sequence (1), or from more differentiated cells that have acquired mutations conferring stem cell-like properties? Given the limited life span of differentiated cells in the intestinal tract, and the requirement of a number of critical events for tumorigenesis, most believe that such events must occur in the stem cells. However, direct evidence was only available recently upon the discovery of intestinal stem cell markers. Several elegant genetic studies indicate that inactivating $A P C$ in the intestinal stem cells, but not in rapidly proliferating progenitors, results in rapid intestinal tumorigenesis in mice $(42,43)$. In our study, these cells are undergoing PUMA- and p53dependent apoptosis following AOM treatment
(Figure. 1C) (7), suggesting that removal of damaged stem cells protects against cancer and such cells as the origin of colon cancer. Moreover, PUMA deficiency increases the incidence of the precursor lesion aberrant crypt foci (ACF) induced by AOM in the colon, or that of microadenomas in the small intestine of $A P C^{\mathrm{Min} /+}$ mice, supporting a stem cell origin in tumor initiation. It remains to be clarified whether or how PUMA contributes to the removal of colonic stem cells under oncogenic stress, presumably upon the loss of the other allele of $A P C$. Stem cell lineage marking mice will help determine the cellular origin of colon tumors and whether that is altered by apoptotic deficiency $(44,45)$.

\section{Does apoptotic deficiency affect mutation spectrum and load?}

The canonical Wnt pathway is invariably activated in human colon cancer due to mutations in 
APC or $\beta$-catenin (46), while mutations in $\beta$-catenin are prevalent in AOM/DSS- or AOM-induced colon cancer in rodents (47). PUMA-deficient tumors acquire fewer activating $\beta$-catenin mutations compared to WT tumors and more aggressive behaviors (7), suggesting that a preexisting deficiency in apoptosis impacts on mutation spectrum or frequencies. Whole genome mutational analysis might help identify genetic alterations cooperating with apoptotic deficiency to promote oncogenesis, leading to a more dynamic view of mutation spectrum in carcinogenesis. Furthermore, similar studies coupled with isolated stem cells will make it possible to answer whether apoptosis affects mutation load in the stem cells to suppress tumor initiation, a long standing question in cancer biology. These types of experiments along with stepwise introduction of mutation, will help better model the multi-step process of carcinogenesis in mice.

\section{Apoptosis as a link between cancer and inflammation}

The AOM/DSS model involves both DNA damage and inflammation, important components in human colon cancer. Epidemiological studies have indicated a clear association between increased cancer risks and chronic inflammation and infections. The risk of developing colon cancer is drastically increased in patients with Crohn's disease or ulcerative colitis. The immune system plays a critical role in tumor promotion and control depending on the stage as well as type of tumors (48). But little is known how it affects tumor initiation. Is there any reason to believe that DNA damage response plays a role? The answer is likely to be yes.

First, immune cells produce various mutagens during inflammation including reactive oxygen and nitrogen species (RONS), which can damage DNA among other macromolecules in the epithelial cells (48). This is supported by a recent study using a similar AOM/DSS model, in which deleting an essential DNA glycosylase Aag1 in the base excision repair (BER) pathway led to enhanced colonic tumorgenesis and increased mutations or base modifications (49). Second, inflammatory cytokines such as TNF-alpha can induce apoptosis of the intestinal epithelium partly through PUMA (50), which sets up an environment for selecting apoptosis-deficient cells. Third, chronic tissue repair and proliferation can overwhelm the endogenous repair capacity leading to fixed mutations. Together, a model is emerging in which defective apoptosis promotes tumorigenesis by enhancing the survival of damaged epithelial cells. Such hypothesis is further supported by our observation that DSS induces PUMA expression in the colonic mucosa in the absence of p53 stabilization (Figure. 2). In addition, stresses such as ROS and ER stress (commonly associated with inflammatory responses) are found to induce PUMA, likely through transcription factors other than p53 $(18,51)$ (Figure. 3). It will certainly be interesting to clarify the role of PUMAmediated tumor suppression in relation to p53 using inflammation-induced tumor models such as $I L-10$ knockout mice or DSS treatment alone. Future work is needed to better understand the interplay between the epithelium and immune system for developing strategies for tumor prevention and treatment.

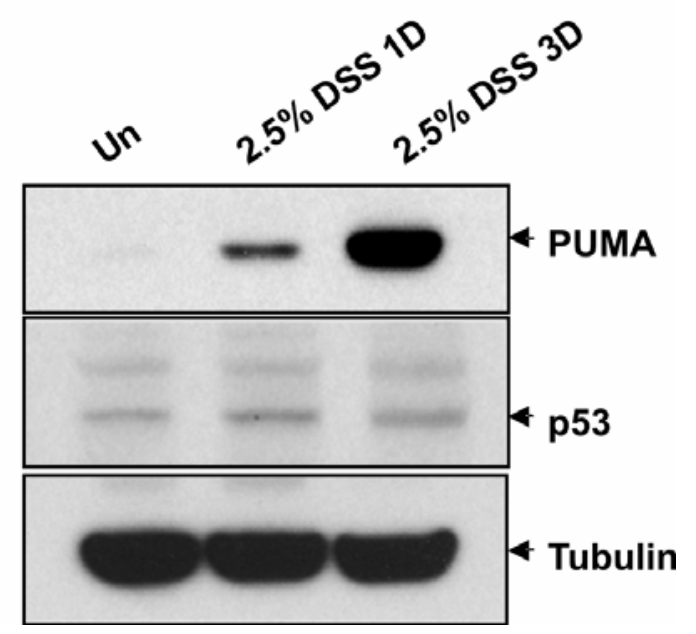

Figure 2. PUMA expression is induced by DSS in the colon. WT mice were subjected to DSS treatment in drinking water for the indicated time, D (day). The levels of PUMA, p53 and tubulin in the intestinal mucosa were analyzed by Western blotting.

\section{Targeting apoptosis in cancer prevention and treatment}

It is believed that the maintenance of tumor phenotypes is highly dependent on suppression of apoptosis triggered by so called "oncogenic stress"(3). The very same alterations leading to tumor initiation and progression contribute to therapeutic resistance $(6,52)$. Conventional chemotherapeutics and radiation primarily target rapidly dividing cells through apoptosis induction. Lack of PUMA induction leads to chemo or radio resistance, while elevated PUMA expression induces profound chemo or radio-sensitization of cancer cells $(11,12)$. The BH3-only proteins including Bim and PUMA have 


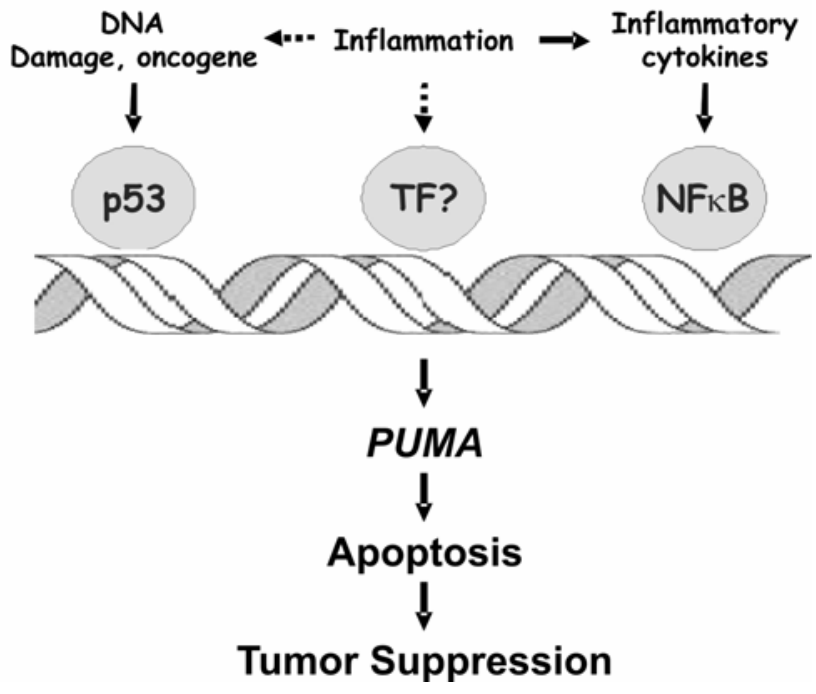

Figure 3. A model of PUMA-mediated tumor suppression. PUMA is activated by transcription factors in response to stress, leading to apoptosis induction and tumor suppression. DNA damage or activated oncogenes induces PUMA through p53 to promote apoptosis. Inflammatory cytokines induces PUMA through $\mathrm{NF} \kappa \mathrm{B}$ to promote apoptosis. DNA damage, inflammatory cytokines and perhaps yet-to-be identified mediators and transcription factors (TF) might provoke PUMA-dependent apoptosis during inflammation.

recently been shown to mediate apoptotic responses to agents targeting oncogenic kinase pathways in cancer cells (27, 53-56). Furthermore, chemopreventive agents such as nonsteroidal antiinflammatory drugs (NSAIDs) can also promote apoptosis in colon cancer cells (20). Together, these observations strongly suggest that eliminating damaged or abnormal cells through PUMA-mediated apoptosis might be useful in preventing and treating cancer (Figure. 3). A growing number of small molecule BH3 mimetics have shown promise in preclinical studies and are now in various stages of clinical testing $(24,57)$. Obviously, apoptosis promoting agents might carry some risks. Too much of it can potentially lead to stem cell exhaustion and premature aging, which was modeled by the "super p53" mice that resist cancer development but age prematurely depending on the dosage and genetic background $(58,59)$. Cautions certainly need to be exercised to find a balance between tumor suppression and aging in cancer prevention or treatment. Losing a few more damaged stem cells is perhaps a price worth paying to stall cancer.

\section{Acknowledgements}

The author wishes to thank Drs. Lin Zhang, Crissy Dudgeon and Brian Leibowitz for critical reading, and Dr. Wei Qiu for help with figures. Work in the author's laboratory is supported by the NIH grant CA129829, U19A1068021 (University of Pittsburgh Center for Medical Countermeasures Against Radiation Developmental Research Program), and grants from the Hillman Foundation, Alliance for Cancer Gene Therapy (ACGT) and Flight Attendant Medical Research Institute (FAMRI)

\section{Conflicts of Interest}

No potential conflicts of interest to disclose.

\section{References}

1. Vogelstein B, Kinzler KW. The multistep nature of cancer. Trends Genet 1993;9:138-41.

2. Vogelstein B, Kinzler KW. Cancer genes and the pathways they control. Nat Med 2004;10:789-99.

3. Hanahan D, Weinberg RA. The hallmarks of cancer. Cell 2000;100:57-70.

4. Hall PA, Coates PJ, Ansari B, Hopwood D. Regulation of cell number in the mammalian gastrointestinal tract: the importance of apoptosis. J Cell Sci 1994;107 ( Pt 12):3569-77.

5. Bedi A, Pasricha PJ, Akhtar AJ, et al. Inhibition of apoptosis during development of colorectal cancer. Cancer Res 1995;55:1811-6.

6. Yu J, Zhang L. Apoptosis in human cancer cells. Curr Opin Oncol 2004;16:19-24.

7. Qiu W, Carson-Walter EB, Kuan SF, Zhang L, Yu J. PUMA suppresses intestinal tumorigenesis in mice. Cancer Res 2009;69:4999-5006.

8. Bunz F, Hwang PM, Torrance C, et al. Disruption of p53 in human cancer cells alters the responses to therapeutic agents. J Clin Invest 1999;104:263-9.

9. Yu J, Zhang L, Hwang PM, Kinzler KW, Vogelstein B. PUMA induces the rapid apoptosis of colorectal cancer cells. Mol Cell 2001;7:673-82.

10. Nakano K, Vousden KH. PUMA, a novel proapoptotic gene, is induced by p53. Mol Cell 2001;7:683-94.

11. Yu J, Yue W, Wu B, Zhang L. PUMA sensitizes lung cancer cells to chemotherapeutic agents and irradiation. Clin Cancer Res 2006;12:2928-36.

12. Sun Q, Sakaida T, Yue W, Gollin SM, Yu J. Chemosensitization of head and neck cancer cells by PUMA. Mol Cancer Ther 2007;6:3180-8.

13. Yu J, Wang Z, Kinzler KW, Vogelstein B, Zhang L. PUMA mediates the apoptotic response to p53 in colorectal cancer cells. Proc Natl Acad Sci U S A 2003;100:1931-6.

14. Yu J, Wang P, Ming L, Wood MA, Zhang L. SMAC/Diablo mediates the proapoptotic function of PUMA by regulating PUMA-induced mitochondrial events. Oncogene 2007;26:4189-98. 
15. Ming L, Wang $\mathrm{P}$, Bank A, Yu J, Zhang L. PUMA dissociates Bax and BCL-XL to induce apoptosis in colon cancer cells. J Biol Chem 2006;281:16034-42.

16. Jeffers JR, Parganas E, Lee Y, et al. Puma is an essential mediator of p53-dependent and -independent apoptotic pathways. Cancer Cell 2003;4:321-8.

17. Villunger A, Michalak EM, Coultas L, et al. p53- and drug-induced apoptotic responses mediated by BH3-only proteins Puma and Noxa. Science 2003;302:1036-8.

18. Wu B, Qiu W, Wang P, et al. p53 independent induction of PUMA mediates intestinal apoptosis in response to ischaemia-reperfusion. Gut 2007;56:645-54.

19. Qiu W, Carson-Walter EB, Liu H, et al. PUMA regulates intestinal progenitor cell radiosensitivity and gastrointestinal syndrome. Cell Stem Cell 2008;2:576-83.

20. Zhang L, Yu J, Park BH, Kinzler KW, Vogelstein B. Role of BAX in the apoptotic response to anticancer agents. Science 2000;290:989-92.

21. Labi V, Erlacher M, Kiessling S, Villunger A. BH3only proteins in cell death initiation, malignant disease and anticancer therapy. Cell Death Differ 2006;13:1325-38. 22. Hoque MO, Begum S, Sommer M, et al. PUMA in head and neck cancer. Cancer Lett 2003;199:75-81.

23. Yu J, Zhang L. The transcriptional targets of p53 in apoptosis control. Biochem Biophys Res Commun 2005;331:851-8.

24. Adams JM, Cory S. The Bcl-2 apoptotic switch in cancer development and therapy. Oncogene 2007;26:132437.

25. Garrison SP, Jeffers JR, Yang C, et al. Selection against PUMA gene expression in Myc-driven B cell lymphomagenesis. Mol Cell Biol 2008;28:5391-402.

26. You H, Pellegrini M, Tsuchihara K, et al. FOXO3adependent regulation of Puma in response to cytokine/growth factor withdrawal. J Exp Med 2006;203:1657-63.

27. Sun Q, Ming L, Thomas SM, et al. PUMA mediates EGFR tyrosine kinase inhibitor-induced apoptosis in head and neck cancer cells. Oncogene 2009;18:2348-57.

28. Ming L, Sakaida T, Yue W, Jha A, Zhang L, Yu J. Sp1 and p73 activate PUMA following serum starvation. carcinogenesis 2008;29:1878-84.

29. Hemann MT, Zilfou JT, Zhao Z, Burgess DJ, Hannon GJ, Lowe SW. Suppression of tumorigenesis by the p53 target PUMA. Proc Natl Acad Sci U S A 2004;101:9333-8.

30. Erlacher M, Labi V, Manzl C, et al. Puma cooperates with Bim, the rate-limiting $\mathrm{BH} 3$-only protein in cell death during lymphocyte development, in apoptosis induction. J Exp Med 2006;203:2939-51.

31. Egle A, Harris AW, Bouillet P, Cory S. Bim is a suppressor of Myc-induced mouse B cell leukemia. Proc Natl Acad Sci U S A 2004;101:6164-9.

32. Vogelstein B, Lane D, Levine AJ. Surfing the p53 network. Nature 2000;408:307-10.

33. Vousden KH, Lu X. Live or let die: the cell's response to p53. Nat Rev Cancer 2002;2:594-604.

34. Vousden KH, Prives C. Blinded by the Light: The growing complexity of p53. Cell 2009;137:413-31.
35. Donehower LA, Harvey M, Slagle BL, et al. Mice deficient for p53 are developmentally normal but susceptible to spontaneous tumours. Nature 1992;356:21521.

36. Wang P, Yu J, Zhang L. The nuclear function of p53 is required for PUMA-mediated apoptosis induced by DNA damage. Proc Natl Acad Sci U S A 2007;104:4054-9.

37. Michalak EM, Villunger A, Adams JM, Strasser A. In several cell types tumour suppressor p53 induces apoptosis largely via Puma but Noxa can contribute. Cell Death Differ 2008;15:1019-29.

38. Hu Y, Le Leu RK, Young GP. Absence of acute apoptotic response to genotoxic carcinogens in p53deficient mice is associated with increased susceptibility to azoxymethane-induced colon tumours. Int $J$ Cancer 2005;115:561-7.

39. Christophorou MA, Ringshausen I, Finch AJ, Swigart LB, Evan GI. The pathological response to DNA damage does not contribute to p53-mediated tumour suppression. Nature 2006;443:214-7.

40. Bjerknes M, Cheng H. Gastrointestinal stem cells. II. Intestinal stem cells. Am J Physiol Gastrointest Liver Physiol 2005;289:G381-7.

41. Potten CS. Stem cells in gastrointestinal epithelium: numbers, characteristics and death. Philos Trans R Soc Lond B Biol Sci 1998;353:821-30.

42. Barker N, Ridgway RA, van Es JH, et al. Crypt stem cells as the cells-of-origin of intestinal cancer. Nature 2008;457:608-11.

43. Zhu L, Gibson P, Currle DS, et al. Prominin 1 marks intestinal stem cells that are susceptible to neoplastic transformation. Nature 2009;457:603-7.

44. Barker N, van Es JH, Kuipers J, et al. Identification of stem cells in small intestine and colon by marker gene Lgr5. Nature 2007;449:1003-7.

45. Sangiorgi E, Capecchi MR. Bmi1 is expressed in vivo in intestinal stem cells. Nat Genet 2008;40:915-20.

46. Clevers $\mathrm{H}$. Wnt/beta-catenin signaling in development and disease. Cell 2006;127:469-80.

47. Takahashi M, Nakatsugi S, Sugimura T, Wakabayashi K. Frequent mutations of the beta-catenin gene in mouse colon tumors induced by azoxymethane. Carcinogenesis 2000;21:1117-20.

48. Coussens LM, Werb Z. Inflammation and cancer. Nature 2002;420:860-7.

49. Meira LB, Bugni JM, Green SL, et al. DNA damage induced by chronic inflammation contributes to colon carcinogenesis in mice. J Clin Invest 2008;118:2516-25.

50. Wang P, Qiu W, Dudgeon C, et al. PUMA is directly activated by NF-kappaB and contributes to TNF-alphainduced apoptosis. Cell Death Differ 2009. [Epub ahead of print] doi:10.1038/cdd.2009.51.

51. Nickson P, Toth A, Erhardt P. PUMA is critical for neonatal cardiomyocyte apoptosis induced by endoplasmic reticulum stress. Cardiovasc Res 2007;73:48-56.

52. Johnstone RW, Ruefli AA, Lowe SW. Apoptosis: a link between cancer genetics and chemotherapy. Cell 2002;108:153-64. 
53. Sordella R, Bell DW, Haber DA, Settleman J. Gefitinib-sensitizing EGFR mutations in lung cancer activate anti-apoptotic pathways. Science 2004;305:1163-7. 54. Gong Y, Somwar R, Politi K, et al. Induction of BIM is essential for apoptosis triggered by EGFR kinase inhibitors in mutant EGFR-dependent lung adenocarcinomas. PLoS Med 2007;4:e294.

55. Costa DB, Halmos B, Kumar A, et al. BIM mediates EGFR tyrosine kinase inhibitor-induced apoptosis in lung cancers with oncogenic EGFR mutations. PLoS Med 2007;4:1669-79; discussion 80.

56. Cragg MS, Kuroda J, Puthalakath H, Huang DC, Strasser A. Gefitinib-induced killing of NSCLC cell lines expressing mutant EGFR requires BIM and can be enhanced by BH3 mimetics. PLoS Med 2007;4:1681-89; discussion 90 .

57. Zhang L, Ming L, Yu J. BH3 mimetics to improve cancer therapy; mechanisms and examples. Drug Resist Updat 2007;10:207-17.

58. Garcia-Cao I, Garcia-Cao M, Martin-Caballero J, et al. "Super p53" mice exhibit enhanced DNA damage response, are tumor resistant and age normally. Embo J 2002;21:6225-35.

59. Tyner SD, Venkatachalam S, Choi J, et al. p53 mutant mice that display early ageing-associated phenotypes. Nature 2002;415:45-53. 